\title{
RESILIENSI DAN ALTRUISME PADA RELAWAN BENCANA ALAM
}

\author{
Gloria Gabriella Melina \\ Aully Grashinta \\ Vinaya \\ Fakultas Psikologi \\ Universitas Pancasila \\ Jalan Srengseng Sawah, Jagakarsa \\ Jakarta Selatan 12640 \\ gaby_melina@yahoo.com \\ aullygrashinta@yahoo.com \\ vi315naya@gmail.com
}

\begin{abstract}
Indonesia is among countries that are vulnerable to natural disasters. Volunteer is someone who has a desire to help others without expecting reward or known as altruism (Myers, 1999). If you see the volunteers, which is expected of individuals who have the capacity to survive even in a difficult situation in a state of disaster. Capacity is referred to as resilience (Maddi \& Khoshaba, 2005). Therefore, this study aims to determine the relationship between altruism with resilience. Participants in this study were 100 volunteers who are members of an Non Government Organization (NGO). Methods of data collection use a scale of resilience and altruism. By using a quantitative approach and the concept of descriptive correlation study Pearson product moment correlation, the result showed that there is a positive and significant correlation between resilience and altruism $(r=.448, p<.01)$ of volunteer. This is means that the higher the resilience, the higher the altruism, vice versa, the lower the resilience, the lower the altruism that is owned by a natural disaster volunteer.
\end{abstract}

Keywords: volunteer, altruism, resilience.

\begin{abstract}
Abstrak
Indonesia adalah termasuk negara yang rentan akan bencana alam. Relawan adalah seseorang yang mempunyai hasrat untuk membantu orang lain tanpa mengharapkan imbalan atau dikenal dengan istilah altruisme (Myers, 1999). Jika melihat relawan, yang diharapkan adalah individu yang mempunyai kapasitas untuk bertahan meskipun berada dalam keadaan yang sulit dalam keadaan bencana. Kapasitas tersebut disebut dengan resiliensi (Maddi \& Khoshaba, 2005). Oleh karena itu, penelitian ini bertujuan untuk mengetahui hubungan antara resiliensi dengan altruisme. Responden dalam penelitian ini adalah relawan bencana alam yang tergabung dalam Lembaga Sosial Masyarakat (LSM) sebanyak 100 orang. Metode pengumpulan data menggunakan skala resiliensi dan altruisme. Dengan menggunakan menggunakan pendekatan kuantitatif dan konsep penelitian deskriptif korelasional Pearson product moment didapatkan hasil bahwa koefisien korelasi anatara variabel tersebut adalah sebesar .448 dan signifikan pada level
\end{abstract}


$.01(\mathrm{p}=.000)$. Hal ini berarti terdapat hubungan yang positif dan signifikan antara variabel resiliensi dengan altruisme pada relawan bencana alam, maka, semakin tinggi tingkat resiliensi, semakin tinggi pula tingkat altruismenya. Begitu pula sebaliknya, semakin rendah tingkat resiliensi, semakin rendah pula altruisme yang dimiliki relawan bencana alam.

Kata kunci: relawan, altruisme, resiliensi.

\section{PENDAHULUAN}

Indonesia adalah negara yang termasuk rentan akan bencana alam. Bisa dikatakan bahwa Indonesia langganan bencana alam, seperti yang paling sering terjadi adalah tanah longsor, banjir, gempa bumi, letusan gunung merapi dan tsunami. Berdasarkan data dari Badan Nasional Penanggulangan Bencana (BNPB), selama kurun waktu 5 tahun (2004-2009), Indonesia telah dilanda bencana alam sebanyak 4.408 kali yang terdiri dari 71 gempa bumi, dua di antaranya mengakibatkan tsunami, selain itu 24 bencana letusan gunung, 469 tanah longsor, 1.916 banjir, 158 banjir disertai tanah longsor, 1.083 bencana kekeringan, 580 angin topan dan 105 gelombang pasang (Alamendah, 2010).

Bencana adalah peristiwa atau rangkaian peristiwa yang mengancam dan mengganggu kehidupan dan penghidupan masyarakat yang disebabkan baik oleh faktor alam dan/atau faktor non alam maupun faktor manusia sehingga mengakibatkan timbulnya korban jiwa manusia, kerusakan lingkungan, kerugian harta benda, dan dampak psikologis (UU No. 24, 2007). Kerusakan infrastruktur dan berkurangnya populasi manusia yang menjadi korban luka-luka bahkan kematian menjadi dampak yang paling terlihat.

Relawan adalah seseorang yang secara ikhlas karena panggilan nuraninya memberikan apa yang dimilikinya (pikiran, tenaga, waktu, harta, dan yang lainnya) kepada masyarakat sebagai perwujudan tanggung jawab sosialnya tanpa mengharapkan pamrih baik berupa imbalan (upah), kedudukan, kekuasaan, ataupun kepentingan maupun karier (Tobing, Nugroho, \& Tehuteru, 2008). Hal-hal yang dapat dilakukan relawan pada saat bencana antara lain rescue (penyelamatan), evakuasi mayat, pelayanan kebutuhan pangan dan sandang, pelayanan kesehatan, mengajak anak-anak korban bencana untuk bermain atau pemulihan sosial psikologis, logistik, serta pendataan.

Dengan kondisi Indonesia yang sangat rawan akan bencana, beberapa LSM pun gencar mencari para relawan yang diharapkan sewaktu-waktu dapat dengan cepat diterjunkan ketika bencana datang. Menjadi relawan bukanlah hal yang mudah karena memutuskan untuk menolong korban bencana alam membutuhkan kekuatan yang besar. Mereka secara drastis dihadapkan oleh realita mengenaskan yaitu bencana alam yang menimbulkan banyak korban. Ketika terjun ke medan bencana, relawan harus memiliki keterampilan praktis agar bisa bertindak secara strategis, seperti kondisi psikologis yang kuat secara fisik maupun mental dan berani untuk menghadapi situasi bencana. Tidak semua orang memiliki kemampuan untuk langsung berhadapan dengan situasi yang tidak tenang seperti pasca bencana. Melihat fakta di lapangan, seperti mengangkat dan mencari mayat-mayat korban bencana alam akan memberikan dampak psikologis yang besar bagi seorang relawan.

Selain merasa terpanggil untuk menolong sesama, menjadi seorang relawan juga harus memiliki kekuatan mental untuk bisa mengevakuasi korban-korban yang luka atau meninggal termasuk memberi pendampingan serta terlibat penuh dalam lingkungan pasca bencana dan lain sebagainya. Menjadi relawan bukan hanya mengangkat korban-korban bencana alam saja, namun juga harus mengatasi kondisi keterbatasan fisik, emosi dan mental. Keterbatasan seperti makanan yang seadanya dan kekuatan 
fisik yang terbatas, pada akhirnya seorang relawan bukan hanya harus menyumbangkan tenaganya untuk menolong korban bencana alam, namun juga harus mampu menolong dirinya sendiri.

Pengaruh usia juga berperan penting dalam menyelesaikan masalah-masalah yang timbul pada kehidupannya. Pada masa dewasa awal dengan rentang umur 20 sampai 40 tahun, individu mencapai puncak perkembangan fisik, intelektual, serta peran sosial (Hurlock, 2000). Individu juga mampu mengatur pemikiran formal operasional dengan baik sehingga memungkinkan untuk merencanakan dan membuat hipotesis tentang masalah-masalah yang dihadapi. Ketika menghadapi masalah, sebagai orang dewasa, individu dapat berpikir logis dan melakukan adaptasi secara pragmatis terhadap kenyataan (Santrock, 2002). Dengan kemampuan-kemampuan ini individu dewasa cenderung dinilai lebih mampu untuk mengembangkan cara-cara yang efektif dalam mengatasi peristiwa yang menekan. Kemampuan merespon secara positif kondisi seperti ini disebut sebagai resiliensi. Dibutuhkan individu dengan tingkat resiliensi tinggi untuk bisa bekerja sebagai relawan yang akan berhadapan dengan berbagai resiko, tantangan dan tekanan. Jika dapat didefinisikan secara jelas, resiliensi adalah kapasitas individu bertahan dan berkembang meskipun berada di dalam situasi yang sulit percaya bahwa individu dapat belajar, berubah, dan mengatasi masalah apapun dalam kehidupan. (Maddi \& Khoshaba, 2005). Maddi dan Khoshaba (2005) mengemukakan tiga dimensi dalam resiliensi yaitu:

1. Komitmen: memiliki tujuan dalam hidup dan keterlibatan dalam pekerjaan, keluarga, masyarakat, sosial, dan lain-lain yang memberikan makna dalam kehidupannya serta melihatnya sebagai hal penting dan layak untuk mendapat perhatian penuh serta memberikan upaya yang terbaik terhadap pekerjaan tersebut walaupun dihadapkan pada situasi yang sulit.

2. Kontrol: kecenderungan individu yang percaya bahwa ia mempunyai kendali penuh untuk mengubah dan menyelesaikan masalah atau kejadian yang dialaminya dibandingkan hanya menjadi korban dari masalahnya. Individu terbuka atas perubahan yng terjadi di luar kendali dan dirinya.

3. Tantangan: melihat perubahan yang terjadi dalam kehidupan sebagai sebuah tantangan atau kesempatan yang mendorong perkembangan kehidupan dibandingkan menghindarinya.

Keinginan untuk menolong sesama dan mempunyai rasa empati adalah modal utama menjadi relawan. Bencana bisa menimpa siapa saja dan menempatkan diri pada kondisi korban bencana juga bisa menjadi motivasi menolong (Saputri, 2008). Hal ini sesuai dengan apa yang dikemukakan oleh beberapa relawan di bawah ini:

"Para relawan dan SAR sudah kelelahan, mereka bekerja dari hari pertama bencana. Medan yang luas dan cukup berat cukup menguras tenaga mereka," (Slamet, 2008)

Kami semua senang menjadi relawan karena sudah jadi dorongan jiwa," (Bayu, 2008)

Fenomena seperti ini dapat menggambarkan seseorang yang memiliki sikap altruisme karena ia mampu merasakan penderitaan orang lain (empati) dan bersedia membantu serta mengutamakan kepentingan orang lain tanpa mengharapkan imbalan. Schroeder, Penner, Dovidio, dan Pillavin (1995) berpendapat bahwa relawan adalah individu yang rela menyumbangkan tenaga atau jasa, kemampuan dan waktunya tanpa mendapatkan upah secara finansial atau tanpa mengharapkan keuntungan materi dari organisasi pelayanan yang mengorganisasi suatu kegiatan tertentu secara formal. Selanjutnya, Badan Nasional Penanggulangan Bencana (2007) mengatakan bahwa relawan penanggulangan bencana adalah seseorang atau sekelompok orang yang memiliki kemampuan dan kepedulian dalam penanggulangan bencana yang bekerja secara ikhlas untuk kegiatan penanggulangan bencana.

Baron dan Byrne (2004) mengemukakan bahwa altruisme merupakan suatu bentuk khusus dari menolong yang dengan sukarela mengeluarkan biaya dan tenaga serta dimotivasi oleh keinginan untuk 
meningkatkan kesejahteraan orang lain dan lebih dari sekedar mendapat reward eksternal. Penelitian Rushton dan Allen (1983) yang mengukur karakteristik altruisme pada relawan, menemukan bahwa relawan mempunyai karakteristik altruisme yang lebih tinggi daripada individu yang bukan relawan. Karakterisitik tersebut antara lain empati, efikasi diri, standar moral yang tinggi, sikap dan emosi yang positif, dan emosi yang cenderung stabil.

Berdasarkan gambaran di atas, maka dapat diasumsikan bahwa penting bagi relawan untuk membangun kapasitas resiliensi yang baik, sehingga ia akan memberikan kemampuannya yang terbaik untuk mencapai tujuannya yaitu menolong korban bencana alam serta dapat mengatasi kesulitan atau hambatan yang terjadi di lokasi bencana alam. Jika tidak, maka individu akan kesulitan dalam mencapai tujuannya. Oleh karena itu, permasalahan dalam penelitian ini adalah "Apakah ada hubungan antara resiliensi dengan perilaku menolong (altruisme) pada relawan?"

\section{METODE}

Partisipan. Partisipan penelitian ini adalah relawan bencana alam yang berada di Jakarta Selatan dan Bogor yang tergabung di dalam LSM atau lembaga kerelawanan yang berusia 20 sampai 40 tahun. Jumlah sampel dari penelitian adalah 100 orang.

Desain. Metode penelitian yang digunakan dalam penelitian ini adalah deskriptif korelasional. Konsep penelitian deskriptif korelasional ditujukan untuk mendeskripsikan atau menggambarkan secara sistematis fakta dari fenomena-fenomena yang ada, khususnya mengenai aspek-aspek yang sedang diteliti (Sukmadinata, 2006).

Prosedur. Teknik pengambilan sampel yang digunakan dalam penelitian ini adalah nonprobability sampling-accidental sampling, di mana individu yang dijadikan sampel tidak mempunyai kesempatan sama bagi setiap unsur atau anggota populasi untuk dipilih menjadi sampel karena ada faktor lain atau karakteristik yang sebelumnya yang sudah direncanakan oleh peneliti.

Teknik Analisis dan Alat Ukur. Penelitian ini menggunakan kuesioner yaitu cara pengumpulan data dengan mempergunakan pertanyaan atau pernyataan tertulis untuk mendapatkan informasi dari responden (Sandjaja, 2006). Pernyataan pada kuesioner ini menggunakan skala sikap tipe Likert dengan 6 rentang jawaban dimulai dari (1) sangat tidak setuju, (2) tidak setuju, (3) agak tidak setuju, (4) agak setuju, (5) setuju sampai dengan (6) sangat setuju. Skala Likert, adalah skala yang digunakan untuk mengukur variabel yang akan diukur dan dijabarkan menjadi beberapa sub variabel dan menjadi komponen yang dapat terukur (Sugiyono, 2002)

Dimensi, definisi, contoh item dan jumlah item dari Skala Resiliensi dapat dilihat pada tabel di bawah ini:

Tabel 1.Dimensi, Definisi, Contoh Item dan Jumlah Item Skala Resiliensi

\begin{tabular}{|c|l|l|c|}
\hline Dimensi & \multicolumn{1}{|c|}{ Definisi } & \multicolumn{1}{c|}{ Contoh Item } & Jumlah Item \\
\hline 1. Komitmen & $\begin{array}{l}\text { Memiliki tujuan dalam hidup dan keterlibatan } \\
\text { dalam pekerjaan, keluarga, masyarakat, sosial, } \\
\text { dan lain-lain yang memberikan makna dalam } \\
\text { kehidupannya serta melihatnya sebagai hal } \\
\text { penting dan layak untuk mendapat perhatian } \\
\text { penuh serta memberikan upaya yang terbaik } \\
\text { terhadap pekerjaan tersebut walaupun } \\
\text { dihadapkan pada situasi yang sulit. }\end{array}$ & $\begin{array}{l}\text { rencant } \\
\text { menyelesaikan pekerjaan } \\
\text { dengan baik. }\end{array}$ & 6 \\
\hline
\end{tabular}




\begin{tabular}{|l|l|l|l|}
\hline 2. Kontrol & $\begin{array}{l}\text { Kecenderungan individu yang percaya bahwa } \\
\text { ia mempunyai kendali penuh untuk merubah } \\
\text { dan menyelesaikan masalah atau kejadian } \\
\text { yang dialaminya dibandingkan hanya menjadi } \\
\text { korban dari masalahnya. Individu terbuka } \\
\text { atas perubahan yng terjadi di luar kendali dan } \\
\text { dirinya. }\end{array}$ & $\begin{array}{l}\text { waktu yang panjang } \\
\text { untuk beradaptasi dengan } \\
\text { lingkungan yang baru. }\end{array}$ & 5 \\
\hline 3. Tantangan & $\begin{array}{l}\text { Melihat perubahan yang terjadi dalam } \\
\text { kehidupan sebagai sebuah tantangan atau } \\
\text { kesempatan yang mendorong perkembangan } \\
\text { kehidupan dibandingkan menghindarinya. }\end{array}$ & $\begin{array}{l}\text { - Saya orang yang } \\
\text { pantang menyerah dalam } \\
\text { menyesaikan pekerjaan } \\
\text { saya. }\end{array}$ & 4 \\
\hline Jumlah & \multicolumn{1}{|l}{} & 15 \\
\hline
\end{tabular}

Sedangkan Dimensi, definisi, contoh item dan jumlah item dari Skala Altruisme dapat dilihat pada tabel di bawah ini:

Tabel 2. Dimensi dan Item Skala Altruisme

\begin{tabular}{|c|c|c|c|}
\hline Dimensi & Definisi & Contoh Item & Jumlah Item \\
\hline 1. Empati & $\begin{array}{l}\text { kemampuan merasakan, memahami, dan } \\
\text { peduli terhadap perasaan yang dialami } \\
\text { oleh orang lain. }\end{array}$ & $\begin{array}{l}\text { - Jika ada korban bencana } \\
\text { alam yang sedang mena- } \\
\text { ngis, saya akan memberi- } \\
\text { nya dorongan agar tidak } \\
\text { terlarut dalam kesedihan. }\end{array}$ & 16 \\
\hline 2.Sukarela & $\begin{array}{l}\text { perbuatan yang dilakukan didasari oleh } \\
\text { tidak adanya keinginan untuk men- } \\
\text { dapatkan imbalan dari orang lain. Tindak- } \\
\text { an ini dilakukan untuk menjunjung nilai } \\
\text { kejujuran dan keadilan pada dirinya. }\end{array}$ & $\begin{array}{l}\text { - Jika tugas saya selesai, } \\
\text { saya menolong teman } \\
\text { saya untuk menyelesaikan } \\
\text { tugasnya. }\end{array}$ & 10 \\
\hline $\begin{array}{l}\text { 3.Keinginan } \\
\text { Membantu }\end{array}$ & $\begin{array}{l}\text { keinginan untuk memberi bantuan kepada } \\
\text { orang yang membutuhkan bantuan mes- } \\
\text { kipun tidak ada orang yang mengetahui } \\
\text { bantuan yang telah diberikannya. Bantuan } \\
\text { yang diberikan berupa materi dan waktu. }\end{array}$ & $\begin{array}{l}\text { - Saya menyediakan waktu } \\
\text { saya apabila ada korban } \\
\text { bencana alam yang ingin } \\
\text { berbincang-bincang. }\end{array}$ & 10 \\
\hline JUMLAH & & & 36 \\
\hline
\end{tabular}

Hasil uji reliabilitas dan validitas dari kedua alat ukur ini diuraikan pada tabel berikut:

Tabel 3. Rangkuman Hasil Validitas dan Reliabilitas Resiliensi dan Altruisme

\begin{tabular}{|l|c|c|c|}
\hline \multicolumn{1}{|c|}{ Variabel } & Nilai Koefisien & & Jumlah Item \\
\hline & Validitas & Reliabilitas & \\
\hline Resiliensi & $.223-.803$ & .810 & $\begin{array}{c}\text { Item }=15 \\
\text { Valid }=15\end{array}$ \\
\hline Altruisme & $.250-.586$ & .874 & $\begin{array}{c}\text { Item }=33 \\
\text { Valid }=33\end{array}$ \\
\hline
\end{tabular}

Penelitian ini menggunakan Pearson product moment correlation untuk menganalisis data. Perhitungan statistik dilakukan dengan menggunakan software SPSS 13.0 for Windows. 


\section{ANALISIS \& HASIL}

Berdasarkan perhitungan korelasi Pearson Product Moment Correlation yang dilakukan, didapatkan hasil $r=.448, p<.01$ Dengan taraf signifikansi $\mathrm{p}(.000)<.01$ maka hubungan antar variabel signifikan dan positif yaitu $\mathrm{r}$ hitung $>\mathrm{r}$ tabel $(.448>.243)$, artinya terdapat korelasi positif yang signifikan antara resiliensi dengan altruisme. Hal ini berarti bahwa semakin tinggi tingkat resiliensi pada subjek, maka semakin tinggi juga tingkat altruisme nya. Dengan demikian, hipotesis alternatif (Ha) yang menyatakan bahwa ada hubungan antara resiliensi dengan altruisme pada relawan bencana alam diterima dan $\mathrm{H}_{0}$ ditolak. Semakin tinggi tingkat resiliensi pada subjek, maka semakin tinggi juga tingkat altruismenya. Menurut Sudjono (2006) besar $r$ hitung antara $.40-.70$ menunjukkan adanya korelasi yang sedang.

Tabel 4.Penyebaran Rentang Skala Resiliensi

\begin{tabular}{|c|c|l|c|c|}
\hline RS & SS & \multicolumn{1}{|c|}{ Kategori } & Frekuensi & Persentase (\%) \\
\hline $15-33$ & $21-46$ & Sangat rendah & - & - \\
\hline $34-52$ & $47-72$ & Rendah & - & - \\
\hline $53-70$ & $73-98$ & Tinggi & 2 & 2 \\
\hline $71-90$ & $99-124$ & Sangat tinggi & 98 & 98 \\
\hline Total & & 100 & 100 \\
\hline
\end{tabular}

Tabel 5.Penyebaran Rentang Skala Altruisme

\begin{tabular}{|c|c|l|c|c|}
\hline RS & SS & \multicolumn{1}{|c|}{ Kategori } & Frekuensi & Persentase (\%) \\
\hline $33-73$ & $11-39$ & Sangat rendah & - & - \\
\hline $74-114$ & $40-68$ & Rendah & - & - \\
\hline $115-155$ & $69-97$ & Tinggi & - & - \\
\hline $156-198$ & $98-125$ & Sangat tinggi & 100 & 100 \\
\hline Total & & 100 & 100 \\
\hline
\end{tabular}

Berdasarkan tabel di atas dapat dilihat bahwa semua responden memiliki tingkat resiliensi dan altruisme yang tergolong tinggi.

\section{DISKUSI}

Penelitian ini bertujuan untuk mengetahui hubungan antara resiliensi dengan altruisme pada relawan bencana alam. Hasil studi menunjukkan adanya hubungan yang signifikan dan positif sedang antara resiliensi dengan altruisme. Hasil penelitian ini mendukung penelitian Rushton dan Allen (1983) yang menyatakan bahwa relawan mempunyai karakteristik altruisme. Dari penelitian ini dapat diketahui bahwa resiliensi juga merupakan karakteristik yang harus dimiliki seorang relawan.

Relawan di dalam penelitian ini terbukti memiliki tingkat resiliensi yang tinggi, sehingga diasumsikan mereka adalah relawan yang mampu berhadapan dengan berbagai resiko, tantangan dan tekanan, termsuk juga emosi-emosi negatif (stressor) yang sering dihadapi relawan. Menurut Enrenreich dan Elliot (2004) stressor yang biasa dialami oleh relawan adalah adanya bahaya mengancam (penyakit, gempa susulan, dan lain sebagainya) yang menimbulkan perasaan takut, berkurang atau hilangnya 
privasi, jauh dari keluarga yang menimbulkan kecemasan pada diri relawan maupun keluarganya, tuntutan fisik yang berat dan kondisi tugas yang tidak menyenangkan, beban kerja yang berlebihan dalam jangka waktu lama, konflik interpersonal yang mungkin timbul di antara anggota kelompok relawan, teringat akan tragedi, kisah, atau cerita-cerita traumatis saat bencana, dan lain sebagainya.

\section{SIMPULAN \& SARAN}

Berdasarkan hasil dari penelitian dapat disimpulkan bahwa terdapat hubungan yang positif dan signifikan antara resiliensi dengan altruisme pada relawan bencana alam. Semakin tinggi resiliensi, semakin tinggi pula altruisme. Secara umum disimpulkan bahwa tingkat resiliensi dan altruisme partisipan penelitian ini berada pada tingkat sangat tinggi.

Saran bagi penelitian selanjutnya sebagai berikut:

a. Melakukan penelitian pada beberapa organisasi kemanusiaan di kota yang berbeda agar penyebarannya lebih luas.

b. Dalam penyusunan alat ukur, diharapkan pada penelitian selanjutnya dapat memodifikasi alat ukur sehingga dapat meningkatkan validitas dan reliabilitas. Khususnya menambah item pada kuesioner resiliensi.

c. Lebih mendalami hal-hal yang dapat mempengaruhi hasil penelitian khususnya resiliensi, seperti pola asuh dan stressor yang dihadapi oleh relawan bencana alam.

d. Menambahkan referensi penelitian mengenai relawan bencana alam.

e. Meneliti perbedaan jenis kelamin pada altruisme relawan.

Saran praktis dapat dijelaskan sebagai berikut:

a. Bagi relawan. Penelitian ini diharapkan dapat menjadi bahan masukan bagi relawan mengenai proses-proses psikologis yang terjadi di dalam dirinya yang terkait dengan resiliensi dan altruisme. Selain itu, para relawan juga dapat mengembangkan kapasitas resiliensi pada diri nya dengan lebih baik lagi agar dapat memaksimalkannya di dalam perilaku menolong atau altruisme.

b. Bagi instansi pemerintahan atau LSM: Disarankan untuk mengadakan program atau kegiatan yang dapat meningkatkan pentingnya resiliensi untuk mendukung sifat altruis dari relawan. Kegiatan dapat berupa pelatihan (training, workshop) dan sharing session kurang lebih enam bulan sekali atau mengadakan program diskusi kelompok yang terdiri dari beberapa orang pada setiap kelompoknya sehingga relawan lebih dapat mengenal satu sama lainnya dan dapat berbagi pengalaman-pengalaman yang dialaminya saat terjun ke lokasi bencana alam.

\section{DAFTAR PUSTAKA}

Baron, R.A., \& Byrne, D. (2004). Social Psychology (10 ${ }^{\text {th }}$ ed). Boston: Allyn and Bacon.

Enrenreich, J.H., \& Elliot, T.L. (2004). Managing stress in humanitarian aid workers: A survey of humanitarian aid agencies' psychosocial training and support of staff. Journal of Peace Psychology, 10, 5-66.

Hurlock E. B. (2000). Psikologi Perkembangan: Suatu Pendekatan Sepanjang Rentang Kehidupan. Jakarta: Erlangga. 
Maddi, S. R., \& Khoshaba, D.M. (2005). Resilience at work: How to succeed no matter what life throws at you. New York, NY: Amacom.

Myers, D.G. (1999). Social psychology (6th ed.). New York: McGraw-Hill

Rushton, J.P., \& Allen, N.J. (1983). Personality characteristics of community mental

health volunteers: A review. Department of Psychology. Advance online publication. doi:10.1177/ 089976408301200106.

Sandjaja, H.A. (2006) . Panduan penelitian. Jakarta: Prestasi Pustaka

Santrock, J.W. (2002). Life-span development (Perkembangan masa hidup) jilid 2. Jakarta: Erlangga.

Schroeder, D.A., Penner, L.A., Dovidio, J.F., \& Pillavin, J.A. (1995). The psychology of helping and altruism: Problems and puzzles. New York: McGraw-Hill.

Sudijono, A. (2006). Pengantar statistik pendidikan. Jakarrta : PT. Raja Grafindo Persada.

Sugiyono. (2002). Metode penelitian kuantitatif, kualitatif, dan R\&D. Bandung: Alfabeta.

Sugiyono. (2002). Statistik untuk penelitian. Bandung: IKAPI.

Sugiyono. (2006). Metode penelitian kuantitatif, kualitatif, dan R\&D. Bandung: Alfabeta.

Sukmadinata, N.S. (2006). Metode Penelitian Pendidikan. Bandung: Remaja Rosda Karya. 2007, UU nomor 24 tahun 2007 Tentang Penanggulangan Bencana.

Tobing, U.R.I.L., Nugroho, F., \& Tehuteru, E.S. (2008). Peran relawan dalam memberikanpendampingan kepada anak penderita kanker dan keluarganya. Indonesian Journal of Cancer, 1, 35-39. Diperoleh dari http://jurnal.pdii.lipi.go.id/admin/jurnal/21083539.pdf

\section{Internet:}

Alamendah (2010) 408 kali bencana alam dalam 5 tahun. Diperoleh dari http://alamendah.wordpress. com/2010/09/18/4-408-kali-bencana-alam-dalam-5-tahun/. Diunduh pada tanggal 28 November 2011 pukul 16.45 wib.

Bayu. (2008). Dari mahasiswa sampai pengusaha, semua jadi relawan.

Kompas 1 April. Diperoleh dari http://www.kompas.com. Diunduh pada tanggal 3 Desember jam 20.05 wib.

Badan Nasional Penanggulangan Bencana. (2007). Definisi Bencana. Diperoleh dari http:www.bnpb. go.id/website/asp/content.asp?id=30. Diunduh pada tanggal 27 Maret jam 20.05 wib.

Badan Nasional Penanggulangan Bencana. (2012). Relawan penanggulangan bencana alam. Diperoleh dari http://bnpb.go.id/website/asp/content.asp?id=68. Diunduh pada tanggal 29 Maret jam 11.13 wib.

Saputri, M. (2008) Jiwa mau menolong itu saja modalnya. Kompas, 10 Agustus. Diperoleh dari http:// nasional.kompas.com. Diunduh pada tanggal 20 November 2011 jam 10.08 wib.

Slamet. (2008). Para relawan dan tim sar mulai kelelelahan. Kompas,1 April. Diperoleh dari http:// www.kompas.com diunduh pada tanggal 4 Desember jam 11.05 wib. 